\title{
Psychological and Pedagogical Conditions for the Formation of Professional Motivation of Social Workers Who Serve the Elderly
}

\author{
Gomonyuk Elena ${ }^{1}$, Kovalchuk Inna ${ }^{2}$ \\ ${ }^{1}$ Faculty of Humanities and Pedagogy, Khmelnytsky National University, Khmelnytsky, Ukraine \\ ${ }^{2}$ Department of Pedagogy and Social Work, Faculty of Pedagogy, Psychology and Social Work, Yuri Fedkovych Chernivtsi National \\ University, Chernivtsi, Ukraine
}

\section{Email address:}

i.kovalchuk@chnu.edu.ua(K. Inna),elena_gomonyuk29@ukr.net(G. Elena)

\section{To cite this article:}

Gomonyuk Elena, Kovalchuk Inna. Psychological and Pedagogical Conditions for the Formation of Professional Motivation of Social Workers Who Serve the Elderly. International Journal of Psychological and Brain Sciences. Vol. 6, No. 5, 2021, pp. 71-76.

doi: $10.11648 /$ j.ijpbs.20210605.12

Received: September 20, 2021; Accepted: October 21, 2021; Published: October 29, 2021

\begin{abstract}
Population aging extends to all spheres of modern society and eliminates new problems that need to be addressed. Among them are demographic, political, economic, cultural, social. The concept of triumphant old age requires a theoretical discussion of concepts and the introduction of modern world achievements in social work with the elderly. Thus, social work in this aspect is an important means of solving problems, both the elderly and the whole community. The leading person in providing services to the elderly is a social worker. Surveys of the elderly, the study of theoretical developments on this issue suggests that so far such work is being conducted at a satisfactory level. The formation of motivation of social work specialists to serve the elderly can significantly improve the situation. The concept of "motivation" covers the internal and external motivational mechanisms of social work of a specialist with the elderly. They are manifested in meeting the professional and personal needs of the social worker, the formation of stable cognitive interests in new technologies of social work with the elderly and in personal self-affirmation. The article examines the external and internal conditions for the formation of motivation of social workers to work with the elderly in Ukraine. Among the external conditions: the state's social policy on institutions providing social services to the elderly, service centers for single disabled elderly people and commercial organizations that provide services to this category of clients; activities of social protection institutions, services for the elderly, including measures related to the provision of additional benefits, services and social benefits to their employees. Among the internal conditions we study: the direction of the specialist to work with the elderly; personal significance of activity, training and retraining of specialists, obtaining emotional satisfaction from work, prevention of burnout. Monitoring of the problem in the Ukrainian environment of social services for the elderly showed an average level of motivation of social workers. To increase it we consider such measures to be appropriate for providing conditions for advanced training and retraining of specialists; their mastery of innovative technologies in this area of social services; creating a psychological climate in accordance with the requirements of social services, and ensuring adequate material support for this area of social services; attention to stimulating the work of specialists, prevention of emotional burnout.
\end{abstract}

Keywords: Elderly People, Psychological and Pedagogical Conditions, Social Services, Social Worker, Motives

\section{Introduction}

\subsection{Relevance of Research}

The aging of the world's population is exacerbating the problems associated with the social services of the elderly, ie people who, according to the WHO classification, are older than 60 years. This group of people often needs daily care for objective and subjective reasons.

Among the objective reasons that increase the need for social services for the elderly, we include: the natural aging of the body, which affects human mobility, endurance, ability 
to be in the air, the ability to see and hear.

Among the subjective ones we can single out illnesses with consequences for health, death of relatives who took care of an elderly person, moving with a family to a new place of residence. Due to these reasons, the role of social services for this category of the population is growing. Under the concept of social services, we understand a set of measures aimed at creating normal living conditions for the elderly.

A survey of the elderly (400 respondents aged 60 to 80 ) showed that almost $45 \%$ of the elderly are dissatisfied with the quality of services provided by social workers.

Based on the analysis of the scientific literature, we highlight the following main problems of low level of social services, namely: low wages for social workers, ignorance of the psychological characteristics of this age group, lack of positive factors of professional motivation.

The demand for ways to solve the problem determines the expediency of a more detailed scientific study of the psychological and pedagogical conditions for the formation of professional motivation of social workers who serve the elderly.

\subsection{Degree of Scientific Development}

Problems of aging in the context of improving the quality of life of the elderly I. Mechnikov, V. Frolkis, I. Davydovsky studied. Among contemporaries it is expedient to allocate scientific works of D. Harman, K. Conson, etc.

Social protection of the elderly was the subject of analysis by E. Lipanova and O. Paliy [12]. O. Sorokina [13], K. Paul [9], L. Postlethwaite [10], Le Thi Thanh Tam [14], M. Kudinova, N. Mugdusiev, and A. Chernysheva [7] A. Klimchuk, A. Mikhailov [6] studieds the current problems of motivating social work specialists to serve. I. Tereshchenko [15], as well as foreign scientists: Barnard C. I. [1]. Scientists pay attention to the mechanisms of formation of motivation of the modern social worker, emphasize the role of studying this phenomenon to improve social policy in general. For example, E. Shane substantiates motivation through the prism of the concept of «culture».

Scientists D. Goldthorpe and D. Lockwood take the orientation of a person to work as the main factor of motivation [4]. L. Porter and E. Lawler analyzed motivation as a combination of personal and corporate goals [11]. We agree with the opinion of scientists N. Danilevich, O. Poplavskaya, Y. Puzyrevskaya [2], A. Klimchuk, A. Mikhailov [6], J. Novikova, L. Watts [8] about that the motivation of the workforce is a possible factor in the development of human capital and the enterprise as a whole.

\subsection{The Purpose of the Article}

Due to the need for a more detailed study of the problem of psychological and pedagogical conditions for the formation of professional motivation of social workers who serve the elderly to improve work in this direction. The research will also be valuable for foreign colleagues studying domestic social work and those who are looking for ways to improve the theory and practice of world experience in this area at the present stage.

\section{Subjects and Methods}

\subsection{Participants}

The respondents were employees of public and private social services that provide services to the elderly. The survey covered the Chernivtsi region, Ukraine These are social workers with more than three years of experience. The study is selective, ensuring representativeness. Respondents were chosen at random. $70 \%$ of respondents have a university degree in "Social Work".

\subsection{Methods}

The study used methods of analysis, synthesis and generalization of scientific sources on the topic. This method allowed us to form a theoretical concept of work. The method of electronic survey facilitates the collection of information from respondents. Mathematical methods provided processing of the obtained results as a result of interrogation of results.

\section{Results}

The study of the process of formation of professional motivation of a social worker to work with the elderly requires a justification of the psychological and pedagogical conditions in which this process will take place. Their characteristics will make it possible to determine the boundaries of the study plane and predict the result. Under the concept of condition, we understand the circumstances that affect the process of forming the motivation of a social worker.

And we consider it appropriate to consider the motivation of social workers to work with the elderly in more detail.

Investigating the motivation of social workers $M$. Kudinova, N. Mugdusiev, A. Chernyshev on the basis of analysis of domestic and foreign scientific thought distinguish three approaches to the analysis of the concept [7].

They study motivation as internal factors that determine human behavior; investigate motivation as a process of external influence on human behavior and analyze it as a psychological state that determines the behavior of the individual. That is, scientists claim that there are internal and external determinants of regulation of the motivational sphere of personality.

In our opinion, the concept of «motivation» covers the internal and external incentives of the social specialist, which are manifested in the social services of the elderly and allow the employee to achieve results in working with this category of clients.

Criteria for positive motivation of social workers who work with the elderly, we consider: the satisfaction of their professional and personal needs, cognitive interest in new technologies of social work with the elderly and personal self-affirmation. 
Analysis of scientific thought allows us to identify external and internal conditions for the formation of motivation of social workers to work with the elderly. External conditions include the following: the state's social policy on institutions that provide social services to the elderly, service centers for single disabled elderly people and commercial organizations that provide services to this category of clients. Scientists M. Kudinova and others. emphasize this component of the formation of positive motivation of professionals to work [7].

An important external condition is the actual operation of social protection institutions, services for the elderly, which includes measures related to the provision of additional benefits, services and social benefits to their employees.

Among the internal conditions are the following: the direction of the specialist to work with the elderly; personal significance of activity, training and retraining of specialists, obtaining emotional satisfaction from work, prevention of burnout.

Consider the real picture of the implementation of these conditions in the social services of the elderly in Ukraine. To verify certain conditions, we conducted a survey of professionals who provide services to the elderly. As a result of an electronic survey, which was attended by 500 social work specialists took part.

The majority of respondents $(45 \%)$ noted that in the context of the spread of COVID-19, traditional measures to motivate social workers who serve the elderly have reduced its effectiveness.

From the point of view of the analysis of activity of experts it is caused by strengthening of requirements to rendering of services against reduction of financing of this work. No less important was the requirement for the specialist and the client to observe personal hygiene and communication hygiene; the tasks of psychological support of the client have changed, the work on medical care and social protection has become more complicated; the number of wards per specialist has decreased.

On the part of clients, the number of negative consequences of social work with the elderly has increased, namely: the mortality rate among the elderly has increased, government spending on this area of social work has decreased, and panic among seniors has spread due to the pandemic.

At the same time, $25 \%$ of social workers (administrative persons) indicated that in 2020-2021 they received moral motivation for good service and material remuneration for work. Among social workers who believe that their work has received a decent reward and the organization's activities motivate them to perform work at a higher level, this figure is much lower, $17 \%$. The main means of motivation, which were actively implemented by the heads of social services, they called: training and retraining in the chosen profession (23\%), additional funding for participation in projects $(34 \%)$, corporate training $(50 \%)$, moral reward for work in the form of gratitude on the occasion of the Day of the Elderly (35\%).

Among the key areas of social policy, the leading role is played by well-thought-out legislation on care for the elderly and a system of incentives for public and private sector professionals. The assessment of the effectiveness of legislation on social services by practitioners on a $100 \%$ scale is $85 \%$. According to experts, the following issues require revision: registration of an elderly person (45\%), determination of the workload of a specialist (58\%), organization of incentives for the work of a specialist (20\%).

An important condition for the formation of motivation of the specialist to work can be called the creation of a social worker's sense of belonging to the organization in which he works. Among the respondents of state social services that provide services to the elderly in Ukraine, $50 \%$ of respondents consider themselves involved in the social service in which they work. Among employees of private institutions serving the elderly, this percentage is lower - $34 \%$.

This indicator can be explained by the commercial goals of private business and low incomes of social workers against the background of their requirements for the provision of services, as well as the authoritarian style of leadership, communication between manager and subordinate type «Chinese wall» or «locator».

Motivation to work increases significantly when the goals and desires of employees coincide with the goals of the organization or meet them. Among the respondents according to this criterion, we obtained the following indicators: $65 \%$ of public sector employees and $25 \%$ of private sector employees have increased motivation to work.

We consider the main measures to improve the situation to identify the need and interest in working with the elderly in job applicants for employment. It can be assumed that those who graduated from a specialized institution in this area of training, this figure will be higher than those who seek to work in this field, but are specialists in other areas.

Regarding the latter, we believe that the motivation to social work with the elderly will be influenced by a common desire to learn how to do this work. This will be facilitated by a flexible work schedule and retraining courses. The interviewees emphasized the advantages of a flexible work schedule in that there is more time for self-realization as a family member and a citizen of society.

An important factor in the formation of professional motivation to work with the elderly is the minimization of layoffs, which will ensure higher productivity, because fear paralyzes the activities of the specialist.

We emphasize that today the content of professional training and retraining of a social worker to work with the elderly should be focused on providing knowledge about the elderly, developing customer service skills in crisis situations, features of socialization and resocialization of clients and ways of client interaction in society.

Foreign experience and practices will be a valuable source in this area. Methods of presenting information should promote the development of the personality of the specialist, stimulate the processes of self-knowledge and self-realization, self-regulation in activities in the chosen direction.

Undoubtedly, the formation of positive professional motivation will contribute to the awareness of the specialist with the information block of activity. This result will be 
provided by trainings, seminars, mutual learning, trips abroad, training in the chosen specialty. A specialist who has experienced a sense of success in academic work has a high level of motivation for practical activities. At the same time, the human factor - love and respect for people of this age group - plays no less a role in the positive motivation of a specialist to work.

The social workers we interviewed illustrated the following answers to this question: $90 \%$ believe that high grades during the training period formed a positive motivation to work; $10 \%$ consider personal interests and the desire for self-affirmation to be the main motivating factors in the work. The results of the survey show that the educational process can provide conditions for selfrealization of the future social worker who works with the elderly, promote the recognition of his individual abilities and the disclosure of talents, reliance on life experience.

In addition to information training, an important role is played by operational training, providing opportunities for professionals to use the technology of social work with the elderly. Important in this context is, first of all, the ability to demonstrate knowledge of methods that would provide the predicted result. Impromptu is important in the activity, but it is desirable to preserve the basis of design, organizational, constructive, communication technologies.

It is important for the performance of the work that the social worker is aware of the goals of the work and the criteria for evaluating its performance, as well as awareness of the remuneration for the work performed. The majority of respondents $(70 \%)$ said that they often do not know the clear rules of the organization's internal regulations and the exact amount of remuneration for work. In theory, these indicators significantly inhibit employee motivation to work. We emphasize that in private organizations these figures are higher than in public ones.

Undoubtedly, the creation of conditions for the participation of social workers not only in the implementation of orders, but also in management work plays an important role in motivating to work with the elderly. For example, participation in the public council of the institution, the conference of the labor collective, the replacement of the management staff for the objective reason of its absence.

Prevention of emotional burnout of a specialist, creation of conditions for exchange of experience between Ukrainian and foreign specialists has a positive effect on motivation. The majority of respondents noted that the exchange of experience was conducted among $60 \%$ of working social workers, and the prevention of emotional burnout among $100 \%$.

That is, such an approach is based on the theory of F. Herzberg, according to which the motivation of the employee depends on two factors: hygienic, ie the available conditions for decent work and motivational factors related to the nature of work and awareness of its content.

Also an important factor in motivating social workers working with the elderly is the factor of the working atmosphere at the enterprise, a favorable socio-psychological climate between the leader and subordinates. It is established that friendly relations between employees, the orientation of the specialist to perform professional duties increase their motivation.

The level of professional motivation increases with a positive image of the service where social workers work.

According to the majority of surveyed clients who use the services of social workers for the care of the elderly, $90 \%$ would entrust their personal space to a specialist who represents the organization with good feedback from friends and clients. And $87 \%$ of social workers said that they work harder when they hear good feedback about the team and the organization as a whole. They argued that this gives confidence in the future and a decent reward for work, as well as contributes to the formation of a positive image of the specialist.

They argued that this gives confidence in the future and a decent reward for work, as well as contributes to the formation of a positive image of the specialist. Thus, the professional motivation of a social worker who works with the elderly is focused on different motives for work: to help an elderly person in going through a difficult period of his life, to assert himself, to fully realize their abilities and talents, to assert himself in public work as an active figure. not only to help the elderly, but also to show competence in other areas of life. It is in this aspect that the motivation of the specialist will have a character that is substantiated in the research of E. Kirchler, K. Rodler, namely: as an individual's willingness to make significant efforts to achieve organizational goals, provided that these efforts contribute to meeting his needs [5].

Among social workers in the private sector, the majority $(65 \%)$ of respondents stressed the importance of improving the quality of services provided to the elderly. The main measures in this direction they called: growth of material remuneration for work $(23 \%)$, creation of improved working conditions $(15 \%)$, providing specialists with individual means of transportation in a pandemic (34\%), providing good information communication with the client $(50 \%)$, reducing the burden on the social worker (35\%). Among the conditions that negatively affect the motivation of a small number of social workers in the private sector is the lack of career opportunities. This was indicated by $11 \%$ of employees.

The generalization of the given data emphasizes the role of socially-oriented management as an important psychological condition for the formation of positive motivation of social workers to serve the elderly.

Fulfillment of this condition will provide a positive image of social work with the elderly in the labor market, increase labor productivity, reduce staff turnover, increase the material well-being of employees, because all indicators of motivation are taken into account.

Scientists from different countries I. Tereshchenko [15], V. Skuratovsky, O. Paliy, E. Libanova [12] O. Sorokina [13], K. Paul, L. Postlethwaite [9], Le Thi Thanh Tam [10], G. Liu R. Huang, C. Zhai [3] identify the following leading areas of 
social wok with the elderly: social assistance and care in inpatient settings; social work with elderly people in territorial centers and day-care centers; social support and care at home; social assistance and social security, that is, the creation of the necessary material and financial conditions to maintain normal life.

Being a popular type, social work with the elderly is at the stage of forming its own concept, which will take into account domestic experience and world practice of social work. It makes maximum use of innovations and innovations in motivating employees to manage and actually work with the elderly.

Each employee, in addition to certain psychological and pedagogical conditions of work in the service, has its own personal motives and incentives, which are manifested through the content of self-education. As a rule, it is focused on self-improvement, the formation of new growths that will contribute to the successful solution of professional problems. Self-control and self-regulation are the vector of these processes, and methodically competent control by the founder or head of the organization in combination with selfcontrol of the head will help to ensure the internal motivation of the specialist to work.

An important psychological and pedagogical condition for the formation of positive motivation is the formation in the organization or social service of favorable organizational conditions for the work of a specialist. They provide a properly equipped workplace; availability of means for various kinds of communications with the client, means for performance of professional activity according to the requirements outlined in documents.

A survey of professionals working with the elderly in Ukraine showed that almost $80 \%$ of public institutions have the conditions for successful work with the elderly. This is an indicator not only of the successful work of leaders, but also of the Ministry of Social Policy. The available sufficient conditions for working with the client are also confirmed by the data of the survey of non-governmental sector employees. Thus, $95 \%$ of respondents point to good financial support for the workplace of a specialist.

In the formation of professional motivation for the work of specialists it is advisable to take into account the gender characteristics of social workers. In this aspect, the role of the factor of double burden on the woman-mother grows. It is a responsibility not only for the successful work, but also for the life and health of their own children. The majority of female respondents surveyed $80 \%$ of the sample believe in the appropriate reduction of the burden on the female specialist.

Among the objective reasons, social workers name the following: the complexity of working with clients due to age changes and limitations of physical activity (78\%), the time spent on the way home to clients in the absence of business transport (65\%). Additional unforeseen factors, they consider difficulties in establishing and maintaining contact with the client, the client's illness, the lack of people who could in their spare time on a volunteer basis to support and continue the work of a social worker (45\%).

Psychological problems of the elderly are: feelings of uncertainty, fear of losing vital energy, sometimes too strong feelings of loneliness and sacrifice, low self-esteem, aggression and anxiety about the future, loss of confidence in material well-being, forced unemployment of elderly families. Therefore, the driving force behind the formation of professional motivation of a social worker should be altruism and the desire for professional self-realization.

The sample of specialists illustrated that for $45 \%$ of social professionals altruism is the basis of professional activity and for $20 \%$ the leading activity is the desire for self-realization in social work with the elderly. However, $15 \%$ of social workers surveyed associate themselves with forced labor in this area, and another $10 \%$ could not answer the question.

\section{Discussion}

The analysis allowed to identify objective and subjective factors influencing the formation of professional motivation of social workers who work with the elderly.

Objective factors include: decent pay and material support system, hygienic working conditions, favorable microclimate in the team, creating training and retraining systems, attention to stimulating the work of a specialist, increasing the role of self-affirmation and self-realization in the profession.

That is, creating conditions for the formation of motivation of social workers to work with the elderly, it is advisable to take into account the concept of D. Goldthorpe and D. Lockwood, who analyze the motivation of professionals as a result of cultural change [4], and the position of M. Kudinova, N. Mugdusiev, A. Chernysheveva, and I. Tereshchenko A. Naumets. Scientists consider motivation as a result of social policy of the state and selfrealization of the individual, the development of its internal stimuli and beliefs [7, 15]. In order to increase the level of motivation of social workers, according to O. Sorokina, it is necessary to improve jobs and expand the scope of activities of employees. This is a division of responsibilities in the organization, in which employees are given more responsibility for its activities as a whole [13].

Among the subjective noteworthy: the health of the employee, the type of social institution that works with the elderly (public or private), the client's financial support, emotional experiences of the specialist, marital status, the desire for self-education, bureaucracy in the field of social care for the elderly. The subjective conditions of motivation can be influenced by changing the orientation of the management of social institutions serving the elderly from administrative to democratic and personality-oriented. This, according to I. Tereshchenko, A. Naumets will allow the employee to be more diligent in the performance of official duties [15].

\section{Limitations of the Study}

Approbation of the questionnaire with the involvement of a larger number of respondents will allow to obtain more 
accurate results, to establish norms of reliability and deviations from them which will further increase the productivity of care for the elderly.

\section{Recommendations}

The study allows us to recommend the developed methodology for implementation in other regions. Taking into account the survey data will preserve the mental health of social workers who work with the elderly and will contribute to the effectiveness of work with the elderly.

\section{Conclusions}

The study of psychological and pedagogical conditions that affect the formation of professional motivation of social workers to work with the elderly has shown a number of problems that need to be addressed urgently and can significantly improve the state of work in this direction. These include: improving the financial support of the public and private sector working in this field, creating a system of incentives and awards for success in work, promoting the participation of social workers not only in customer service but also in the management of the organization of training in the profile and exchange of interstate and domestic experience, providing a flexible work schedule, freeing up specialist time by simplifying paperwork, increasing the level of material well-being of the elderly. The experience of Vietnam, described by Le Thi Thanh Tam, can be considered positive in the latter [14].

\section{Prospective Research}

We consider the development of methods for testing certain psychological and pedagogical conditions to be prospects for research in this direction.

\section{References}

[1] Barnard C. I. (1938) The Functions of the Executive. Cambrige (MA): Harvard University Press, 384 p.

[2] Danilevich N. S., Poplavskaya O. M., Puzyrevska Y. O. (2019) Motivation of young professionals: features, recommendations. Economic space, 142, pp. 53 - 64. doi $10.30838 /$ p.es.2224.260219.53.378.
[3] Guilin Liu, Ruiying, Huang, Cuiqiu Zhai \& Yunjia Li. (2019) An Investigation of the Knowledge, Attitude and Practice of Family Caregivers of Patients with Alzheimer's Disease International Journal of Psychological and Brain Sciences, 4, 1, February, pp. 1-6. doi: 10.11648/j.ijpbs.20190401.11.

[4] Goldthorpe, J., Lockwood D., Bechhofer F., \& Platt, J. (1968). The affluent worker: political attitudes and behavior. Cambridge: Cambridge University Press.

[5] Kirchler E., Rodler K. (2003) Management in organizations / Per. with him. H.: Izd-vo Humanitarian Center, 128 p.

[6] Klymchuk A. O. \& Mikhailov A. N. (2018) Motivation and stimulation of staff in effective management Enterprise and increase of innovative activity. Marketing and Innovation Managemen, 1, pp. $218-234$.

[7] Kudinova M. M., Mugdusiev N. K., \& Chernysheva, A. S. (2017) Motivation of work as an tool of social policy. Efficient economy, $4 . \quad$ Available at: http://www.economy.nayka.com.ua/?op=1 \&z=5543 (accessed 01.09.2021).

[8] Novikova, J \& Watts, L (2015), Towards Artificial Emotions to Assist Social Coordination in HRI', International Journal of Social Robotics, 7, 1, pp. 77-88. Available at: https://doi.org/10.1007/s12369-014-0254-y (accessed 01.09.2021).

[9] Paul K. N, Kim (1991) Server the Elderli: Skill of practice, Aldin de Gruyter. New York, 334 p.

[10] Postlethwaite Liz (2018). Treasury of arts activities for older people. The Baring Foundation. London, 120 p.

[11] Porter L. W. \& E E. Lawler (1968). Managerial Attitudes and Performance, Homewood: Richard D. Irwin, 209 p.

[12] Skuratovsky V. A, Paliy O. M \& Libanova E. M (2003). Social policy. Kiev; Textbook, 343 p.

[13] Sorokina O. A. (2016) Motivation of activities of social services. Proceedings of the XIII International Scientific Internet Conference "Modernity. Science. Time. Interaction and interaction. November 16-18 2016. Kiev, pp. $99-104$.

[14] Tam Le Thi Thanh. (2018) Social work with the elderly in Vietnam. Social and labor relations: theory and practice, 1, pp. 191-196.

[15] Tereshchenko I. I. Naumets A. M. (2011) Personalities of social work with the elderly in the conditions of modern Ukraine. Bulletin of NTUU «KPI». Politology. Sociology. Law: a collection of scientific papers, 3 (11), pp. $113-117$. 